\title{
Basaliom unvollständig entfernt? Sofort nachschneiden!
}

\author{
Stellt sich nach Exzision eines Basalioms heraus, \\ dass die Schnittränder nicht tumorfrei sind, \\ sollte der behandelnde Kollege nicht lange \\ warten. Unmittelbares Nachschneiden ver- \\ ringert Rezidive, die ggf. eine ausgedehnte \\ Resektion erfordern. Dies gilt besonders für \\ ästhetische Problemzonen ...
}

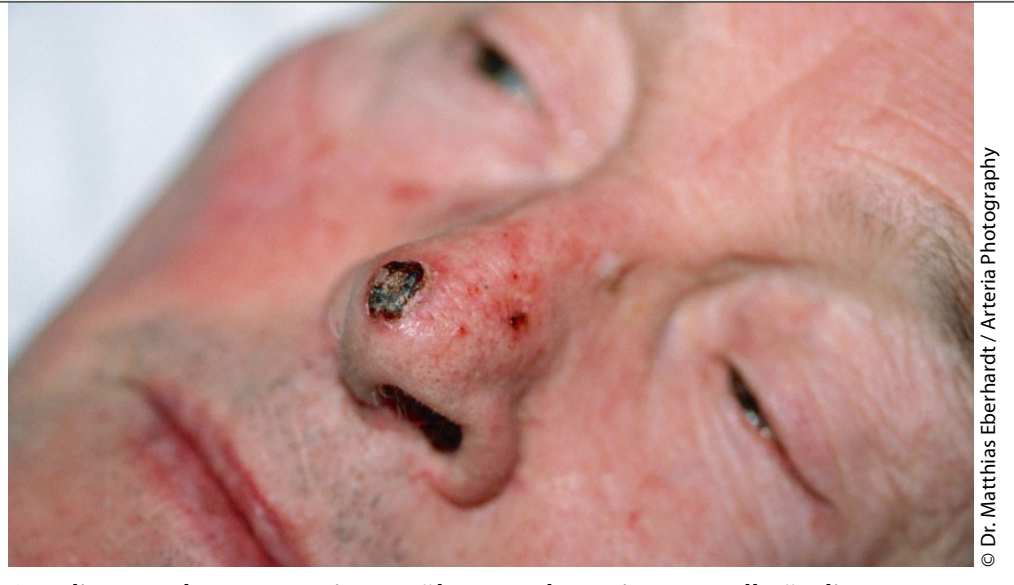

Basaliom an der Nasenspitze: Frühe Korrektur einer unvollständigen Exzisionen verringert die Folgeschäden.

V anessa Palmer und ihre Mitarbeiter vom Londoner St. Thomas Hospital analysierten die Daten von 100 Patienten mit unvollständig reseziertem Basalzellkarzinom. Diese Tumore behandelten die Kollegen nach der Mohs-Technik mit spezieller Exzision, histologischer Kontrolle und ggf. unmittelbarer Nachresektion.

In 69\% der Fälle fanden sich Tumorreste in den Randschnitten bei der Reexzision. 27,5\% der Tumore lagen im Bereich der Nase, die Wangen waren in $24,6 \%$ betroffen. Basaliome der Stirn oder der Schläfe lagen in 17,4\% der Fälle vor. Tumorlokalisation im Bereich der Lippe und des Kinns waren in $8,7 \%$, im Bereich der Ohren in 7,2\% dokumentiert. Knapp die Hälfte der Basalkarzinome wurde histologisch als infiltrativ klassifiziert, jeder dritte Tumor war nodulär.

Fazit: Die Autoren der Studie fordern, bei positivem Tumornachweis im Schnittrand gleich erneut zu resezieren anstatt abzuwarten. Dies gelte gerade dann, wenn der Tumor an ästhetisch auffälligen Stellen des Gesichts lokalisiert ist. Vor al- lem hier sollte man Rezidive vermeiden, die dann einen noch wesentlich aufwendigeren Eingriff erfordern. Palmer et al. plädieren dafür, das Mohs-Verfahren in allen Fällen einer unvollständigen Exzision anzuwenden. Insbesondere bei einer geplanter Lappenplastik müsse man sich über die Tumorfreiheit hundertprozentig sicher sein.

Dr. Elke Oberhofer

Palmer VM et al. Incompletely excised basal cell carcinoma: residual tumor rates at Mohs re-excision. Dermatol Surg 2013 Jan 7 [Epub ahead of print]

\section{Rezidiv trotz negativem Sentinel}

\section{Auch bei negativem Befund in den Sentinellymphknoten kann es zu Melanomrezidiven kommen. Welche Patienten besonders gefährdet sind, haben Kollegen der University of Colorado untersucht.}

$\mathrm{n}$ ihrer retrospektiven Studie analysierten Edward Jones et al. von der University of Colorado die Daten von $515 \mathrm{Me}$ lanompatienten, die sich zwischen 1996 und 2008 einer lokalen Tumorexzision mit negativer Biopsie der SentinelLymphknoten unterzogen hatten.

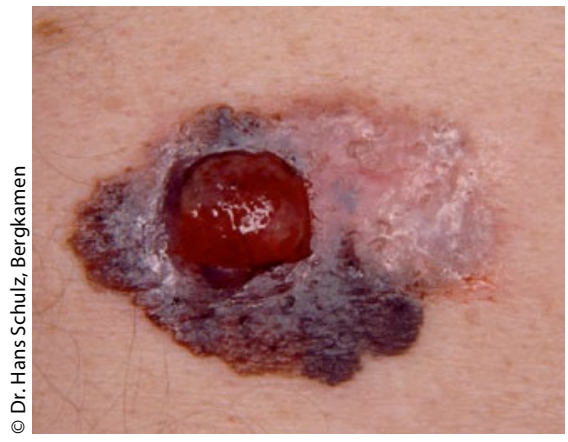

Malignes Melanom (SSM IV)
83 Patienten (16\%) erlitten Rezidive, dabei waren 21\% im Abstromgebiet des untersuchten Sentinel-Lymphknotens gelegen. Dies entsprach einer Rate falsch negativer Befunde von $4 \%$.

Die mittlere Breslow-Dicke der Läsionen mit späteren Rezidiven betrug 2,7 $\mathrm{mm}$, verglichen mit $1,8 \mathrm{~mm}$ bei nicht rezidivierenden Tumoren. Später rezidivierende Melanome waren zudem häufiger ulzeriert (32,5\% vs. $13,5 \%)$.

Primärtumoren im Kopf- und Halsbereich waren ebenfalls ein Risikofaktor: 42,2\% der Patienten mit - gegenüber 17,2\% der Patienten ohne Rezidiv - hatten ihre Melanome in diesem Bereich. Männliches Geschlecht (27 vs. 9\%) und höheres Alter (57 vs. 49\%) erwiesen sich ebenfalls als ungünstige Faktoren.

Das Auftreten von Fernmetastasen verschlechterte die Prognose deutlich.
Lag die Fünf-Jahres-Überlebensrate in der gesamten Gruppe mit negativem Sentinelbefund bei $91 \%$, sank sie nach Auftreten von Rezidiven auf 64\%. Die Lokalisation spielte dabei keine wesentliche Rolle.

Im Median trat das Rezidiv nach knapp zwei Jahren auf, konnte sich aber auch mehr als acht Jahre nach der Erstdiagnose noch entwickeln.

Fazit: Die Rate der falsch negativen Sentinel-Lymphknotenbiopsien lag in dieser Studie bei $4 \%$. Als Risikofaktoren identifizierten die Autoren tiefer infiltrierende Tumoren, Ulzeration, im Kopf-HalsBereich gelegene Läsionen sowie männliches Geschlecht und hohes Alter.

Die Autoren betonen, dass bei einer Beschränkung der Nachuntersuchungen auf nur fünf Jahre knapp 11\% der Rezidive übersehen worden wären.

Dr. Robert Bublak

Jones EL et al. Long-term follow-up and survival of patients following a recurrence of melanoma after a negative sentinel lymph node biopsy result. JAMA Surg 2013 Jan 16 [Epub ahead of print] 